\title{
Educar sob coação: uma sociologia da justiça juvenil
}

\author{
Veridiana Domingos Cordeiroa
}

SALLÉE, Nicolas. Éduquer sous contrainte: une sociologie de la justice des mineurs. Paris: Éditions de l'EHESS, 2016.

O livro Éduquer sous contrainte: une sociologie de la Justice des Mineurs, publicado pela Éditions de l'EHESS, foi lançado em agosto de 2016 pelo professor do Departamento de Sociologia da Université de Montréal, Nicolas Sallée, que se dedica aos estudos acerca da regulação de conduta juvenil. O livro não é extenso (conta com 226 páginas), mas apresenta reflexões históricas, teóricas, dados empíricos de segunda mão e dados empíricos diretos.

A pesquisa é parte de uma série de reflexões dedicadas aos modos de controle do comportamento juvenil, envolvendo a construção de políticas públicas, produção e disseminação do conhecimento, sobretudo na França do século XX e início do XXI.

O tratamento judicial de jovens na França é regulado pelo decreto de abril de 1945, que tem cunho paternalista e institui a Éducation Surveillée $e^{1}$ (que em 1990 vem a se chamar Protection Judiciaire de la Jeunesse - PJJ) como uma divisão administrativa autônoma do Judiciário. Essa divisão, composta de um corpo de educadores, é um marco político que representa a "vontade de ruptura dentro de um setor que era assombrado pela existência das 'colônias penitenciárias', rebatizadas, por um decreto de 1927 de 'casas de educação supervisionada' " (SALLÉE, 2016, p. 16).

Desta maneira, o livro foi dividido em duas partes: a) uma retomada histórica que explora a política educativa da PJJ desde 1945, flertando com a história mais geral do tratamento da conduta juvenil na França nos séculos XX e XXI e b) a análise do trabalho institucional dos educadores junto aos jovens delinquentes ligados à Protection Judiciarie de la Jeunesse ${ }^{2}$ (PJJ), tanto em instituições abertas quanto fechadas. A primeira parte do livro é resultado de uma pesquisa bibliográfica de arquivos, documentos históricos e judiciais sobre o tema e a segunda é resultado de observações participantes em serviços educacionais para menores em conflito com a lei existentes na França, que são de três tipos: serviço educacional em meio aberto, um centro educativo fechado e uma prisão para menores.

a Bacharel e licenciada em Ciências Sociais pela Universidade de São Paulo, mestre em Sociologia pela Universidade de São Paulo e doutoranda em Sociologia pela Universidade de São Paulo.

1 Educação Supervisionada.

2 Proteção Judiciária da Juventude. 
Esses serviços têm início com o texto de 1945 que rompe ${ }^{3}$ com os princípios jurídicos do Código Penal de $1810^{4}$, que considerava o menor como um responsável penal. Embora o decreto de 1945 tenha se tornado um símbolo do humanismo, de um modelo que prima pela "educação" em detrimento da "repressão", seu texto inicial é ambíguo e está longe de realmente abolir a ideia de "responsabilidade penal”. Isso gerou uma tensão que vem permeando a justiça de menores na França: por um lado, a multiplicação de liminares punitivas como respostas penais cada vez mais duras para jovens delinqüentes, e, por outro, o contínuo esforço de alguns atores (educadores e alguns parlamentares) para preservar um tratamento da delinquência juvenil baseado em uma educação formativa. Sallée irá, portanto, analisar os rumos que tomou o desenvolvimento do modelo educacional a partir do decreto de 1945, o qual, em um primeiro momento, foi um contraponto ao tratamento penal dado aos jovens até então, mas que, ao longo das décadas, ganhou contornos pautados na ideia de "responsabilização" do jovem, legitimando assim o uso da coerção e da reclusão:

[...] desde a criação dos centros educativos fechados em 1996, seguidos dos centros de reclusão em 2002, até a abertura de novas prisões especificamente dedicadas a menores em 2006, esse modelo - que nós qualificamos como uma 'educação sob coerção' - redesenha a paisagem de uma justiça para menores sob o peso de uma utopia disciplinar revitalizada (SALLÉE, 2016, p. 18; em livre tradução).

O nascimento da PJJ é resultado de uma série de disputas que tiveram palco na primeira metade do século XX. A categoria "delinquência juvenil”, não apenas na França, como em outros lugares do mundo 5 , foi por muito tempo um guarda-chuva para uma série de outras formas de desvio, tais como "anormalidades", "deficiências" ou “inadaptações". Vemos, então, o início de uma "luta por território" em que várias áreas do saber passam a tentar definir a categoria "delinquência

3 Essa ruptura não aconteceu de uma hora para outra, mas foi fruto de um processo que vinha se desenrolando nos anos anteriores, como por exemplo, a emergência da ideia de "assistência educativa" que entra na lei de 30 de outubro de 1935 e que progressivamente vai se desenvolvendo até 1945 .

4 Desdobramento posteriores do Código de 1810 resultam, por exemplo, em tribunais exclusivos para menores (13-18 anos) - algo que também pode ser encontrado no Canadá e nos Estados Unidos na mesma época (TRÉPANIER, 1999).

5 Mesmo após a promulgação do primeiro Código de Menores no Brasil, em 1927, menores abandonados (não necessariamente em desacordo com a lei) eram recolhidos pelas autoridades (Alvarez, 1989). 
juvenil". Até o texto de 1945, o Ministério da Educação e o Ministério da Justiça disputavam a responsabilidade sobre essa categoria. Após o surgimento da PJJ, em 1945, não cessaram, no entanto, as disputas, as quais passaram a girar no interior da própria PJJ para definir o tipo de saber que prevaleceria para o tratamento desses jovens. Primeiramente, a Psicanálise disputava com a Neuropsiquiatria infantil quais seriam os métodos e exames apropriados para o diagnóstico desses jovens. Mais tarde, os profissionais das Ciências Sociais passam a defender uma "sociologização" da explicação da delinquência juvenil associada a um "tratamento" psicanalítico. Esse casamento disciplinar recebeu uma legitimação institucional a partir da criação do Centre de Formation et Recherche de l'Éducation Surveillée ${ }^{7}$ (CFRES), em 1958. Este reaviva a Sociologia Criminal na França, cruzando uma multiplicidade de variáveis (macrossociais, psicossociais e psicológicas) para questionar a correlação entre o nível de delinquência juvenil e o nível de desenvolvimento socioeconômico. Embora houvesse uma disputa pelos saberes, os educadores sempre foram o tipo de profissional que perdurou e prevaleceu na PJJ desde o seu nascimento, fazendo parte inclusive da administração da PJJ8.

Dentro da PJJ, inicialmente havia duas frentes de atuação para os educadores. Institutions Spéciales d'Éducation Surveillée (ISES) ${ }^{9}$ e os Centres d'Orientation et d'Action Éducative (COAE) ${ }^{10}$. A ISES é uma alternativa ao encarceramento para jovens condenados a menos de um mês de prisão. Essa instituição traça estratégias educativas personalizadas para cada jovem ${ }^{11}$. O COAE é responsável por acompanhar e investigar os jovens em seu próprio ambiente (em meio aberto) a fim de fornecer um diagnóstico educativo, isto é, é um serviço de colocação ${ }^{12}$.

Embora os educadores tivessem tido força e expressão na PJJ desde 1945, a partir da década de 1990 algumas mudanças importantes aconteceram. Em meio aos discursos públicos de clamor punitivo, denominados "populismo penal” ${ }^{13}$, a

6 Autores como Émile Durkheim, Gabriel Tarde e Gaston Richard eram evocados para apontar explicações sobre as causas sociais do crime.

7 Centro de Formação e Pesquisa da Educação Supervisionada.

8 De acordo com as estatísticas levantadas por Sallée, entre 1948 e 1958 os educadores passaram de $39,4 \%$ para $48,6 \%$ dos profissionais que compunham a PJJ.

9 Instituições Especiais de Educação Supervisionada.

10 Centros de Orientação e Ação Educativa.

11 De acordo com uma pesquisa de 2008, Sallée afirma que 8.5\% dos 5.00o educadores da PJJ estavam atuando nessa instituição.

12 De acordo com uma pesquisa de 2008, Sallée afirma que 25\% dos 5.00o educadores da PJJ estavam atuando nessa instituição.

13 O populismo penal diz respeito a um conjunto de discursos que, em nome da vítima, buscam radicalizar o direito de punir. Essa emergência da figura vítima nos debates públicos fortaleceu, como consequência imprevista, um impulso repressivo, que passa a canalizar todos os grandes problemas da sociedade pelo âmbito penal, por exemplo, voltando-se para medidas repressivas contra a delinquência juvenil (CARIO; SALAS, 2001). 
administração da PJJ sai das mãos dos educadores, quando é criada uma administração com concursos disponíveis a profissionais de diferentes áreas, como juristas e administradores. Vemos ainda, na década de 1990 e na década subsequente, a abertura de mais centros educativos fechados e de prisões para menores, redesenhando profundamente a paisagem da PJJ e as identidades profissionais que eram historicamente associadas a ela. Nessa década, testemunhamos um contexto histórico internacional de crescente luta contra a "insegurança”, que acabou por capturar os debates públicos sobre a delinquência juvenil. No centro desse debate, atores centrais a ele (como juristas e policiais), alinhados a um sistema de justiça repressor, trazem de volta a ideia de "responsabilidade penal dos menores". Em contrapartida, parlamentares e educadores pediram uma revisão do texto de 1945 que atenuasse a ideia de responsabilidade penal, a fim de equilibrar o debate e as medidas que começaram a ser tomadas na PJJ. A ideia de justiça restaurativa - na época amplamente disseminada nos Estados Unidos - invade os debates em torno da PJJ, trazendo uma visão enviesada em que a justiça restaurativa passa a ser um instrumento de uma política criminal conservadora, que visa uma responsabilização penal ${ }^{14}$.

As instituições de meio fechado foram reabertas a partir de 2002, após a vitória da direita nas eleições presidenciais em um contexto no qual os republicanos prometiam "segurança" para a França. Essas instituições são de dois tipos: os Centres Éducatif Fermés (CEF) ${ }^{15}$ e os Établissements Pénitenciaires pour Mineurs (EPM) ${ }^{16}$. Embora os CEFs tenham sido criados sob o discurso de não serem um local de detenção, mas sim de residência, eles nada mais são do que as antigas colônias penitenciárias reformadas, que se tornaram "escolas profissionalizantes", onde os jovens internados podem obter um certificado de aptidão profissional. Aqui, os educadores (com exceção dos professores técnicos responsáveis pelas aulas) adotam uma pedagogia inspirada no escotismo, herdada dos métodos disciplinares presentes nas colônias penitenciárias da década de 1920. De acordo com Sallée, esses centros são "uma regressão histórica” (2016, p. 141). Os EPMs, por sua vez, são verdadeiras cadeias para jovens de 13 a 18 anos. Eles estão sob responsabilidade da administração penitenciária e são estruturados com celas, mas recebem o trabalho de educadores da PJJ. É com a construção desse

14 De acordo com Taylor et al. (1980), a justiça restaurativa, que tem por objetivo a restauração das relações envolvidas na percepção de conflito e sua resolução a partir de formas mais consensuais, por vezes ganhou contornos enviesados imputando uma ideia de punição aos envolvidos.

15 Centros Educativos Fechados

16 Estabelecimentos Penitenciários para Menores. 
contexto em mente que Sallée inicia seu trabalho de campo em instituições da PJJ de meio aberto e de meio fechado.

No meio aberto, os educadores constroem problemáticas para prover diagnósticos acompanhados de projetos de reinserção social. Essas problemáticas são construídas a partir de reuniões semanais em que cada educador compartilha os seus casos - cada educador é responsável por cerca de oito jovens. A análise tem uma estrutura pré-fixada em que se analisam seis aspectos da vida do jovem: a) sua situação judicial; b) sua composição e dinâmica familiares; c) sua situação escolar; d) sua situação socioeconômica; e) sua situação médica; ef) seu ambiente. Sallée percebe, ao longo da análise dos educadores, que há sempre uma tentativa de conferir coerência à trajetória dos jovens. A partir de trechos inteiros retirados das reuniões que o autor transcreve com precisão, ele vai demonstrando como os diagnósticos são extremamente subjetivos e psicologizantes, na medida em que os educadores invocam traumas familiares e outros argumentos psicológicos para explicar a situação dos jovens. Essas narrativas coletivamente construídas acerca da vida dos jovens vêm carregadas de interpretações altamente moralizantes.

No meio fechado, Sallée realiza pesquisa nos CEFs e nos EPMs. Os jovens que são encaminhados para o CEF normalmente são aqueles que não respeitaram ou fugiram de sua colocação feita pelo COAE. Sallée conclui que os meios utilizados para o tratamento dos jovens no CEF não são educativos, mas sim psíquicos e/ou materiais. As ações propagadas no interior dos CEFs são basicamente de cunho carcerário a fim de manter a ordem, constranger os problemas internos e de evitar a evasão. Quaisquer rastros de educação no CEF são meramente comportamentais, atendendo uma "pedagogia de módulos" (SALLÉE, 2016, p. 151), que é sustentada por uma ideia de responsabilização e um caminho de progressão a ser seguido pelo jovem. Para essa progressão são mobilizados critérios meritocráticos e morais em relação às condutas dos jovens. Entrevistas realizadas com educadores dos CEF mostram como esse modelo de encarceramento e enquadramento por módulo é uma ameaça ao trabalho educativo que é o propósito dos CEFs.

$\mathrm{O}$ trabalho dos educadores nos EPMs não tem a mesma abrangência que nas outras instituições, pois aqui eles dividem o espaço com os vigilantes penitenciários e a instituição não está voltada para uma ação educativa. Poucas atividades educacionais e recreativas são organizadas pelos educadores e conversas com os jovens estão focadas em construir uma preparação para quando eles saírem da instituição.

O mapeamento da PJJ, entrelaçado com pontes históricas sobre o tratamento da conduta juvenil na França e completado pela observação participante em insti- 
tuições da PJJ, possibilita que Sallée nos traga um bom panorama da atividade educacional para adolescentes em conflito com a lei. A partir da retomada histórica, Sallée conclui que se desenvolveu, no interior da PJJ, uma educação pautada no Direito Penal e animada por uma economia moral baseada em um imperativo de responsabilização do jovem. Se os educadores estão, a todo momento, buscando compreender o ambiente social e familiar dos jovens como a verdadeira causa de seus comportamentos delituosos, a ideia de uma educação sob coerção (éducation sous contrainte) passa inevitavelmente a ser pano de fundo da atividade educativa. Nela está implicada uma ambivalência que, por um lado valoriza o indivíduo, mas por outro o responsabiliza e o socializa de maneira disciplinar.

\section{REFERÊNCIAS BIBLIOGRÁFICAS}

Alvarez, Marcos César. Emergência do código de menores de 1927: uma análise do discurso jurídico e institucional da assistência e proteção aos menores. Dissertação de Mestrado em Sociologia. Faculdade de Filosofia, Letras e Ciências Humanas da Universidade de São Paulo, 1989.

CARIO, Robert; SAlas, Denis. CEuvre de justice et victimes. Paris: L’Harmattan, 2001.

TAYLOR, Ian; WALTon, Paul; Young, Jock. A criminologia crítica na Inglaterra: retrospecto e perspectivas. In: TaYlor, Ian; Walton, Paul; Young, Jock (Org.) Criminologia Crítica. Rio de Janeiro: Graal, 1980, p. 1-72.

TRÉPANIER, Jean. Juvenile Courts after 100 years: past and present orientations. European Journal on Criminal Policy and Research (7): p. 303-327, 1999. 